\title{
From Study Abroad to Global Studies: Reconstructing International Education for a Globalized World
}

\section{Theodore E. Long \\ Elizabethtown College, Emeritus}

In the spring of 1962, I was finishing my freshman year at a university that had no overseas study programs. Fortunately, I was a member of the choir that toured Europe that summer, a remarkable experience highlighted by singing in East Berlin behind the newly erected wall. Two years later, the choir toured East Asia, another peak experience for me. In addition to sight-seeing and singing, usually in churches or at military bases, both tours included home stays, instruction in local culture, drinking, and ambassadorial events, also sponsored primarily by church or military. Those experiences were formative in developing my personal orientation to the world, evoking an enduring interest in other cultures and a deep commitment to peaceful understanding among peoples.

Since then, study abroad has become a substantial enterprise as educators embraced the idea that learning about other cultures is a critical component of becoming an educated person, succeeding at work, and serving as an effective citizen (Bok, 2006). Many students report that study abroad has been a transformative life experience, just as my trips were. Studies now show that study abroad is positively related to student persistence and success, and liberal educators purport that it is an essential element of learning for personal and social responsibility (Association of American Colleges \& Universities.). In some important ways, though, the educational value of study abroad today does not seem to be dramatically different than what I got from my first college trips. Beyond my own experience, scholarly assessments have concluded that the empirical evidence for the effects of study abroad is weak (Pascarella and Terenzini). Here I attempt to understand this apparent lack of real progress and impact in study abroad and how we can transcend its limitations. I will address these issues from a broad perspective, focusing on defining structures and central tendencies, not specific activities or programs.

Ironically, the great success of study abroad has exposed three major limitations in its fundamental educational character that appear to have been embedded in the project from the outset. First, "study" has typically been subordinated to experience. Second, student studies abroad are largely 
derivative of their home curricula, not expressive of any coherent design that represents global educational priorities. Third, study abroad has primarily expressed a homeland perspective in an emerging world that is pushing toward a more cosmopolitan global order, not a genuinely global perspective. As a result, the current approach cannot deliver an education most responsive to the needs and possibilities of a globalized world. To do so, we must reconstruct international education on new foundational principles, at the heart of which lie 1) a genuinely global perspective that informs the development of 2) a coherent program of Global Studies that has its own integrity and in which 3) study guides experience. That reconstruction will define a new set of possibilities for collegiate education to foster a critical perspective on the globe, to help students grasp new possibilities for themselves, and to promote productive global citizenship. And it will bring into clear focus just why global studies must be engaged with issues of peace and justice as critical aspects of global civil society.

\section{The Educational Limits of Study Abroad}

When we look at how study abroad operates and how students respond to it, it is not hard to see how its educational power has been limited. In the first instance, it is clear that "study" takes second place to being "abroad" for students, study being a necessary but not the defining feature of the undertaking. For them, the whole point of going abroad is to experience a foreign culture, not to have a distinctive academic experience. Indeed, rarely have I heard the "study" itself mentioned by students as being among the highlights of their experience abroad. Rather, they refer most often to the experiences of seeing new sights, meeting new people, confronting a different culture and navigating a strange land as highlights. Moreover, students have a difficult time articulating just what it is that they learned from these experiences, but they know for sure that the experience was powerful in some way. While study abroad surely adds to their knowledge base, it is the contrast of cultures that motivates students, draws their attention, and evokes their emotion.

The extensive adoption of experiential educational methods in collegiate instruction over the past generation has largely undercut the debate about the relative virtues of study vs. experience in international study (Hoffa, 2007), which now often employs such experiential learning strategies in overseas programs itself. That trend has provided some useful academic discipline to students' experience, but it has not altered the priority of the experiential side for them. If anything, it has enhanced the value of experience, because students can now also get academic credit for their primary activity of engaging another culture. Such combinations also highlight the continued absence of systematic 
learning goals, disciplined pedagogical strategies, and outcomes assessment in the co-curricular experience of study abroad, where we know relatively little about whether or what students actually learn.

Why do they study at all, then? As a practical matter, students could enjoy their experience abroad (more or less guided) without studying, and some do just that by dropping out for a while or traversing the world after graduation before settling down. Most of them take the opportunity to combine study with overseas experience for three reasons: 1) to fulfill academic requirements, 2) to stay on track for timely graduation, or 3) to maximize the value of the money they spend on education. Historically, even the most academically serious "junior year abroad" programs of an earlier era were primarily enrichments to or extensions of the home curriculum in languages or the arts. Today, students can study many more subjects in many more places, but still those studies primarily do the bidding of the home curriculum. Increasingly, home curricula include a global dimension, so students often study something about their host culture, and they frequently take courses designed specifically to address distinctive issues at the study site. In that respect, student studies have happily become more focused on the realities of the world "abroad," and participants actually return with some substantive knowledge of that wider world to satisfy curricular expectations at home.

Dependence on the home curriculum's definition of what is important to learn and how it should be learned ensures that the educational component of study abroad is also quite fragmented, just as US curricula have become. There are many options but no center, and even attractive and meaningful program elements tend to become just one among many that rarely are integrated into a coherent whole. Indeed, the derivative educational logic of study abroad has driven it toward greater educational incoherence even as it has multiplied the number of attractive program options for students. This remains true even for the international dimensions of the home curricula, which rarely achieve coherence themselves. As much as we applaud American higher education's interest in the wider world, we should also recognize that international study takes its cues from the educational culture it serves. In so doing, it sacrifices the opportunity to articulate a thoroughly globalized educational program of its own, and de facto aligns its cognitive perspective with the home campus.

Historically, both collegiate curricula and study abroad have been under the sway of what I will call a homeland perspective, which is oriented to the world from the vantage point and interests of the homelands it serves and the homelands where students learn, usually nation-states. As a niche in the global order, homelands are protected territories with normative cultures and authoritative social orders. They foster mono-cultural identities and rely on 
conventional action to sustain community, to which people must assimilate in order to belong. Those who are not assimilated are experienced as alien. Interestingly, study abroad attacks that final assumption of the homeland perspective by demonstrating that alternative cultures have their own integrity as homelands that are both understandable and coherent. In so doing, it has served as a liberalizing force for understanding among peoples rather than reinforcing the antagonism toward other cultures promoted in a traditional homeland perspective. That remains an important work even today, but it has not liberated study abroad from its homeland perspective. For the ideals of cultural immersion that promote understanding among peoples, appreciation of other cultures, a broader perspective, a more worldly and culturally adept citizenry still express a homeland perspective on what is significant about overseas experience, albeit a liberalized one.

Well, "what's so bad about that?" you might ask. Capitalizing on students' interest in new experiences, study abroad has collaborated with colleges and universities to build a liberalizing educational experience that will enhance our society as it meets the global challenges of the future. "Quite impressive" many would say, and I would certainly applaud those achievements on their own terms myself, for they constitute a positive step toward a more civilized world. But there are further steps that need to be taken if we are to address the educational needs and human possibilities of a globalized world, and study abroad as we know it is limited in its capacity to do so by the very features that have sponsored its success. The most significant limitation of the enterprise is that it has not developed a coherent educational approach built around an understanding of how the world has changed through globalization. As a result, study abroad a) does not enable students to grasp the distinctive character of the globe as an entity; b) does not fully emancipate them from the takenfor-granted, as the best liberal education does; and c) does not reach for the highest ideals of humankind that are exposed in a global world. "The globe" is now a social entity in its own right, "a single place" as Robertson (1992) has noted, and it differs in significant ways from the homelands that have shaped international education's cognitive interests and educational program to this point. For study abroad to reach its greatest educational possibilities in this new era, it will need to adopt a global perspective and build a coherent educational enterprise responsive to the needs and interests of a global order. Let me sketch one coherent way to do so, recognizing there can certainly be alternative formulations that would accomplish the same thing.

\section{A Global Perspective for International Education}

Just what would such a global perspective look like, and in what way can 
it be a genuinely educational perspective, not political or economic? In light of study abroad's dependence on others' educational programs, it is important to be clear about the type of educational perspective that would serve international study best among the several that could be adopted. I would argue strongly that the most fruitful education for the globe will be developed within a program of liberal education, one that is not merely technical or appreciative but genuinely "liberating" or "emancipatory" by virtue of cultivating critical thought, self-reflection, and a sense of social responsibility. It is an education that does not merely accept the world and oneself as they appear but aspires to test and shape them for the better. Contrary to much public opinion, liberal education eschews political indoctrination in favor of skepticism; against academic orthodoxy, it is not limited to the humanities and social sciences but can be embedded in all disciplines; and despite its "ivory tower" image, it is demonstrably practical as well as uplifting.

As Don Harward has summarized it, "liberal education comprises three interrelated and essential dimensions: the epistemic, the psychosocial, and the civic" (Harward, 2012, 9). The epistemic dimension focuses on the development of knowledge and its uses: knowledge about the world, knowing how to do things, and how best to apply knowledge to action. The psychosocial dimension "focuses on the integration of learning and its connection to the full development of the learner" in a way that promotes individual well-being (Harward, 2012, 11). The civic dimension connects learning to life in the promotion of an ethic of responsibility to use knowledge for the betterment of world around us. These three elements are part of all liberal education programs, but their substance will differ substantially in a truly global perspective, in contrast to a homeland viewpoint. In a global perspective, the epistemic dimension of education concentrates on the globe as a realm of life in its own right, having been generated from the historic process of globalization. In its psychosocial dimension, a global perspective focuses on cosmopolitanism, which defines the type of personal identity and the interpersonal ethic characteristic of a global world. Along the civic dimension, global citizenship becomes the focus of international education. Let me consider each in turn.

\section{The Epistemic Dimension: Understanding "The Globe"}

Roland Robertson has aptly described what has happened in the process of globalization as the "relativization" of all the structures of life on our planet. Historically we have understood life to be organized around two main poles, national societies and individual selves. The society provided security and a normative order for individuals, who in turn offered their allegiance to the 
community and contributed their effort toward its advancement. Globalization created a world system of societies beyond the national society, and evoked an understanding of a worldwide humankind beyond individual selves. In so doing, globalization created a condition in which none of those four major elements could consider its own character as being given in the nature of things or all-sufficient for life. In a world system, no society can consider itself complete in itself or authoritative in relation to others, and its claim on citizens is compromised by their potential allegiance to humankind. Likewise, a singular self-identity is relativized in light of humankind, and the locus of appropriate individual effort is complicated by the world-system of societies.

The globe has thus become like an intersecting and overlapping set of borderlands where there are many homelands jousting for position in contested territories in which social order must be negotiated. That does not mean that homelands disappear or abandon their efforts to define life in their territory; rather, their local ways are countered with other ways in a dialectic of universalizing forces and particularizing interests. For individuals, this reality fosters plural identities and requires creative action from them, not just conventional behavior, to sustain community, where people must accommodate one another in order to live together peacefully. Those who are not part of the community are not alien, but simply strangers who have not been encountered before. It should be clear that focusing overseas study on these fundamental features of the globe would not only make a homeland perspective problematic, but would evoke different types of curricula as well. Likewise, taking a homeland perspective in a global context casts one in the role of an interested participant in the global drama, whereas analysis of the globe itself treats its many participants more evenhandedly, understanding each on the same basis rather than highlighting one particular set of interests. To be sure, a global perspective has cognitive and normative interests of its own that many ardent "homelanders" would resist, but it is the strongest basis for claiming a compelling and distinctive educational perspective for international educators.

Those distinctive features of the globe as a single entity demonstrate the importance of developing a global perspective in its own right, but alone, they are insufficient to underwrite a genuine global curriculum. That requires the identification of the globe's many features that express its nature and functioning and then integrating them into a comprehensive picture of the globe as an entity analogous to the way we have understood national societies. The fact that those various global phenomena are already addressed in various academic niches does not ensure that they express a global perspective that understands them as part of a system of global dynamics and functioning. For 
example, for years sociologists have studied population dynamics within and among nations - urbanization, migration, assimilation, etc. - and we know a great deal about those phenomena as a result. We know far less, however, about how migration patterns operate to change global sustainability or how they create or alter global networks of innovation and development. Those are the type of questions that arise from a thoroughgoing interest in the globe itself, and international educators are uniquely positioned to frame a compelling conception of those issues that can guide curriculum development for a global education.

\section{The Psychosocial Dimension: Nourishing Cosmopolitanism}

Consistent with our individualistic focus, we homeland educators ordinarily concentrate on the personal side of psychosocial development, the identity and character of each individual. In so doing, we often neglect the interpersonal features of life which shape us as individuals and define how we are able to build community. When community itself is problematic, however, as it is in a globalized world, we cannot focus solely on the personal aspects of development, even to understand how global identities differ from homeland identities. Instead, we must also understand how strangers with substantial personal differences can engage one another in order to live together productively. Using a term now in vogue, I will consider both global identity formation and global community formation as dual aspects of "cosmopolitanism."

Considering identity formation in the context of immigration, Carola Suarez-Orozco $(2004,173)$ points out that "the ability to formulate an identity that allows comfortable movement between worlds will be at the very heart of achieving a truly 'global soul'" (embedded quote from Iyer, 2000). Noting the typical expectation that a normal identity is singular and whole, she suggests that globalization ensures that "most people in the world now develop a bicultural identity,' which incorporates elements of the local culture with an awareness of a relation to the global culture" (Suarez-Orozco, 2004, 196, embedded quote from Arnett, 2002, 777). She also concurs with Gates' view that "the idea of wholeness has largely been retired. And cultural multiplicity is no longer seen as the problem but as a solution - a solution to the confines of identity itself. Double consciousness, once a disorder, is now a cure." (Gates, 2003, quoted by Suarez-Orozco, 2004, 196). In sum, engagement with the globe increasingly fosters plural cultural identities, cosmopolitan identities if you will, rather than the culturally singular identities previously considered the norm. And global education's call is to serve as mid-wife in the birth of such identities, helping mono-cultural students become genuinely cosmopolitan. 
The other side of cosmopolitanism is what Appiah calls "ethics in a world of strangers" (2006), the ways we fashion to live together through all our differences. The burden of his thinking centers on the dialectic of universalism and particularism in globalized social relations. Against those who believe they have identified a universal truth that should be implemented for everyone and those who believe in tolerating all differences so everyone can live her own way, Appiah argues for a complex combination of universal ideals and tolerance of difference. Cosmopolitans believe in universal truth but are realistic about "how hard the truth is to find" (Appiah, 2006, 144); likewise, they are committed to tolerance of difference but believe that every human has obligations to every other because of our common humanity, which sharply limits the scope of our tolerance. So a cosmopolitan ethic combines just one simple universal principle of obligation to others with a tolerance of individual human beings in specific life situations where we live together, not by persuading or coercing the other to live like us, but by finding some daily practices that enable us to live in peace. This is not so much a matter of competence in communicating across differences as it is a matter of focusing ongoing conversation on the practical matter of how we live together as we engage strangers.

\section{The Civic Dimension: Fostering Global Citizenship}

The idea of global citizenship, however intuitively appealing, has been difficult to grasp conceptually because it has appeared to have no tangible referent analogous to the nation-state, within which citizens ordinarily are accorded citizenship rights and responsibilities. With a more robust understanding of the globe, however, we can begin to sketch the contours of a genuinely global citizenship independent of the nation-state. While there is no global entity like the nation state, global citizenship involves the same elements as state citizenship, but they are inverted. In the nation-state, citizenship is conferred by membership therein, which defines who may legitimately participate in collective life and make claims on collective goods. In the globe, however, people from multiple homelands encounter situations where no one group can define who is legitimate, so global citizenship is claimed on the basis of common human rights, which purport to authorize anyone to participate in creating collective goods. While they do not abandon their national citizenship, global citizens incorporate it within a larger framework of global interests and outlooks. Much more than voting or expressing views, global citizenship requires the active engagement of individuals in collective action to create humane and peaceful ways of living together.

Considered purely on an individual basis outside the context of the nation-state, global citizenship would be a very fluid status, shifting on the 
basis of virtually every new encounter. Recently, however, scholars have developed an understanding of the normative and institutional frameworks of the globe that can buttress and provide a context for a more robust global citizenship. David Held's conception of "cosmopolitan order" identifies eight normative principles that support robust and effective global citizenship, grounded in the idea that a global citizen has a right "to present oneself and be heard within and across political communities" and "to enter dialogue without artificial constraint and delimitation of power" (Held, 2010, 68). On that basis, he suggests the necessary institutional requirements for the effective implementation of those principles in the realms of law, politics, economics and culture across the globe, not to create a super nation-state but to embed the principles in these institutional sectors at a global level.

Mary Kaldor's conception of "global civil society" also identifies an institutional space for global citizenship. In her analysis, globalization has undermined the singular identity of national civil societies by bringing new participants into the realm of civil society and undermining the distinction between civil and uncivil societies, thereby calling into question the nationstate as the exclusive province of civil society. She defines civil society, national or global, as "the medium through which one of many social contracts between individuals and the political and economic centers of power are negotiated and reproduced." (Kaldor, 2003, 44-5) Such contracts result from a civil public conversation among a wide array of actors, individual and collective, in which reasoned discourse generates agreements. In the globe, civil society is "a process of management of society that is 'bottom-up' rather than 'top-down' and involves the struggle for emancipatory goals" that involve "a new generation of rights " and the creation of a system of "global governance" constituted by "overlapping authorities"(Kaldor, 2003, 142-3). Global civil society thus provides "an answer to war" because it establishes alternatives to war as a basis for securing civil order, which had been the historic pattern of nation-states.

\section{Peace and Justice}

By now it should be clear that unlike the world of the nation-state, the possibility of peace and justice is a fundamental problematic and ideal of the globe. In nation states, internal peace and justice is taken for granted but is effectively secured by force to protect the security of its citizens and their capacity to enjoy lives of peace and just treatment, as defined in that society. As the explication of global citizenship demonstrates, however, the capacity to sustain peaceful relations is not only fundamental to the effective functioning of cosmopolitan order and global civil society, which establish the possibilities for productive global citizenship, but peace is also essentially uncertain because 
there is no sure guarantor for global order. Likewise, these social forms and global citizenship itself are built on a fundamental commitment to justice in the form of human rights. So at a minimum, fostering global citizenship will involve educating students about the possibilities of sustaining peace and realizing human rights, as well as the process of doing so. But peace and justice issues also infuse all three dimensions of a global education, just with different emphases. Along the epistemic dimension, the question about peace and justice concerns their character and empirical possibilities. In psychosocial education, they gain relevance as conditions of identity formation and productive human interaction. In global education, peace and justice are not electives; they are required study and practice for all.

\section{For a New Program of Global Studies}

The framework outlined above constitutes a coherent perspective that can sponsor an engaging and attractive curriculum of the globe. It is the foundation stone for reconstructing international education in a way that reaches beyond the limitations of study abroad to provide a compelling program of study for a globalized world. By adopting it, or something similar, international educators will establish an intellectual and philosophical standpoint of their own that transcends the homeland perspective and can provide academic guidance for student experience overseas, but also at their home institutions. The work of transcending existing practice and realizing the ideals sketched above can best succeed in a two-pronged process: 1) reforming study abroad to transcend its existing limitations, and 2) repositioning study abroad as part of a larger program of "global studies" to realize the larger possibilities of this global perspective.

Reforming and extending study abroad will be most effective by proceeding gradually, introducing new initiatives that eventually replace or convert existing practices. Some specific practices that accent the new global perspective include the following:

- Deliver a global curriculum at every site

- Select study sites to highlight global issues and phenomena

- Send students to multiple sites, not just one

- Study abroad more than once

- Have students do research on global issues while abroad

- Engage students with borderland experiences

- Make peace and justice issues an aspect of all overseas study

- Confront students with practical issues of cosmopolitan identity and ethics 
- Place students in NGOs as a normal practice

- Organize (dis)course work across borders

- Integrate study abroad about the globe with home institution study of the globe

An increasing number of programs are already embracing such practices, a robust sign that the pieces of a truly global perspective are already seeded in the field of international education. At the same time, they remain pieces of a puzzle that has not yet been fully assembled as a coherent whole. The major step we can take to integrate existing initiatives would be to enlarge the conception of our work by changing its name from "study abroad" to "global studies," and enlarging the scope of its program accordingly. Doing so would extend the understanding of what international education is all about by articulating a broad educational purpose, not just finding a different place to study, and it would specify what we are about by delineating a specific subject for this educational program, "the globe" and all its distinctive structures and ramifications, rather than remaining dependent on home curricula. Even as we are building up new practices in study abroad, we should also work to establish this new supportive framework within which new study abroad practices and other global curricular initiatives can take root and flourish.

Once in place, the idea of "global studies" itself opens some attractive new possibilities for international curricula. Even though it is focused on the globe, for example, the study of the globe need not always entail travel abroad; it can be done at the home institution or some other site in the homeland where global phenomena are salient. Likewise, "global studies" suggests the possibility of a program of study that could extend throughout a college career, one for which students could receive formal academic credentials and certification. Most of all, advancing the idea of "global studies" would stake a claim for educational leadership in the academy by international educators themselves, creating the opportunity to turn even the best international programs toward a focus on the distinctive character of the globe as a central element of every college's academic program. If that could be accomplished, we would not only strengthen study abroad significantly but also reshape higher education itself toward a higher vocation for this global century. 


\section{References}

Association of American Colleges and Universities, "Liberal Education and America's Promise" (www.aacu.org/leap).

Appiah, Kwame Anthony. (2006) Cosmopolitanism: Ethics in a World of Strangers (New York: Norton).

Arnett, J.J. (2002) “The Psychology of Globalization," American Psychologist 57:10: 774-783.

Bok, Derek. (2006) Our Underachieving Colleges. (Princeton: Princeton University Press).

Gates, H.L., Jr. (2003) “Both Sides Now," New York Times Book Review (April 4).

Harward, Donald W. (2012) "The Theoretical Arguments and Themes," in Donald W. Harward, ed., Transforming Undergraduate Education:

Theory That Compels and Practices That Succeed (New York: Rowman and Littlefield) 3-33.

Held, David. (2010) Cosmopolitanism: Ideals and Realities (Cambridge, UK: Polity Press).

Hoffa, William W. (2007) A History of US Study Abroad: Beginnings to 1965 (Special issue of Frontiers: the Interdisciplinary Journal of Study Abroad and the Forum on Education Abroad).

Hoffa, William W. and Stephen C. Depaul, eds. (2010) A History of US Study Abroad: 1965 - Present (Special issue of Frontiers: The Interdisciplinary Journal of Study Abroad).

Iyer, P. (2000) The Global Soul (New York: Vintage).

Kaldor, Mary. (2003) Global Civil Society: An Answer to War (Cambridge, UK: Polity Press).

Suarez-Orozco, Carola. (2004) "Formulating Identity in a Globalized World," in Marcelo M. Suarez-Orozco and Desiree Baolian QinHilliard, eds., Globalization: Culture and Education in the New Millenium (Berkeley: University of California Press) 173-202.

Pascarella, Ernest T. and Patrick T. Terrenzini. (2011) "Some New Evidence on What Matters in Student Learning," plenary address at the Council of Independent Colleges Institute for Chief Academic Officers (www.cic.org).

Robertson, Roland. (1992) Globalization: Social Theory and Global Culture (London: Sage). 